\title{
Moxifloxacin in Complicated Skin and Skin Structure Infections (cSSSIs): A Prospective, International, Non- Interventional, Observational Study
}

Johannes R. Bogner • Ammar Kutaiman •

Melanie Esguerra-Alcalen • Stephanie Heldner •

Pierre Arvis

To view enhanced content go to www.advancesintherapy.com Received: February 20, 2013 / Published online: June 25, 2013

(c) The Author(s) 2013. This article is published with open access at Springerlink.com

\begin{abstract}
Introduction: ARTOS was an international, prospective, non-interventional, noncontrolled observational study designed to determine the effectiveness, safety, and tolerability of moxifloxacin under daily-life conditions in patients with complicated skin and skin structure infections (cSSSIs) treated in
\end{abstract}

J. R. Bogner $(\varangle)$

Infektionsabteilung Med Klinik und Poliklinik IV, University Hospital of Munich, Munich, Germany e-mail: Johannes.Bogner@med.uni-muenchen.de

A. Kutaiman

Department of General and Vascular Surgery,

Al Noor Hospital, Abu Dhabi, UAE

M. Esguerra-Alcalen

Department of Surgery, San Juan De Dios Hospital,

Pasay City, Philippines

S. Heldner

Bayer Pharma AG, Berlin, Germany

P. Arvis

Bayer Santé, Loos, France

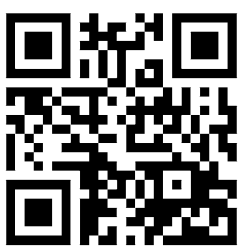

Enhanced content for Advances in Therapy articles is available on the journal web site: www.advancesintherapy.com
Europe, the Middle East, and Asia-Pacific region.

Methods: Eligible patients included males and females who were hospitalized patients or outpatients requiring antibiotic therapy for cSSSIs and for whom the treating physician had elected to begin moxifloxacin therapy in accordance with its approved indications. Patients were assessed before therapy and then at one or two follow-up visits. Effectiveness was assessed with respect to improvement and resolution of signs and symptoms of cSSSIs and safety with respect to the nature and frequency of adverse events and adverse drug reactions.

Results: A total of 6,594 patients were enrolled of whom 5,444 had data available for analysis; 4,692 patients received sequential intravenous/ oral (IV/PO) moxifloxacin and 752 exclusively IV therapy. A majority of patients were aged between 40 and 79 years and had one or more comorbid conditions. Post-surgical wound infection, skin abscess, and diabetic foot infection were the cSSSIs most frequently diagnosed and treated with moxifloxacin, with almost $90 \%$ of infections rated moderate or severe. Treating physicians chose sequential 
moxifloxacin $400 \mathrm{mg}$ for most patients, switching from IV to PO after 3-4 days. On average, treatment was maintained for 10 days. Treatment with moxifloxacin was associated with rapid relief in symptoms, with $93.2 \%$ of patients experiencing either complete resolution of symptoms or improvement at follow-up. Moxifloxacin was well tolerated with adverse drug reactions occurring in only $2 \%$ of patients.

Conclusions: This study, conducted in a 'realworld' setting, confirms the effectiveness and safety of moxifloxacin in the treatment of a wide spectrum of cSSSIs seen in routine clinical practice.

Keywords: Broad-spectrum antibiotic; Complicated skin and skin structure infections; Fluoroquinolones; Moxifloxacin; Observational study

\section{INTRODUCTION}

The skin and underlying soft tissues are frequent sites of bacterial infection and one of the most common reasons for administering antibiotic therapy. Skin and skin structure infections (SSSIs) range from relatively benign, uncomplicated conditions (e.g., carbuncles, impetigo) to complicated SSSIs [cSSSIs, e.g., major abscesses, traumatic wounds, and diabetic foot infections (DFI)]. cSSSIs are generally distinguished from uncomplicated SSSIs by the need for surgical debridement and drainage in addition to antibiotic treatment [1]. At their most severe, cSSSIs can include potentially limb- or life-threatening infections such as necrotizing fasciitis. Consequently, the management of cSSSIs is complex with the need for additional surgery, adequate treatment of comorbidities, antibiotic therapy, prolonged hospitalization, and lengthy convalescence [25].

The etiology in most cases is bacterial prompting for empirical intravenous (IV) antibiotic therapy against the most likely causative pathogens [6]. In the most serious cases, patients may also need fluid resuscitation and organ support, along with revascularization or limb amputation if severe ischemia is present [6]. Underlying conditions such as diabetes, peripheral vascular disease, chronic venous insufficiency, and compromised immune systems may complicate or curb the response to antibiotic therapy $[1,6]$; management of such conditions must, therefore, be addressed in the course of treatment.

Both Gram-positive bacteria and Gramnegative bacteria are implicated in cSSSIs. Staphylococcus aureus is the most frequently isolated Gram-positive pathogen and the most common cause of cSSSIs [4, 7], although $\beta$ hemolytic streptococci are also common and are often associated with rapidly spreading infections such as erysipelas or cellulitis [1]. Pseudomonas aeruginosa and Escherichia coli are the most frequently isolated Gram-negative bacteria in cSSSIs [7]. Mixed infections are common, especially in patients with major abscesses and DFI, where staphylococci, streptococci, Enterobacteriaceae, and Gramnegative anaerobes, such as Bacteroides spp., may be isolated [8].

The antibiotic recommendations in guidelines reflect the diverse nature and etiology of bacterial infections of the skin and skin structures [1, 9-13]. Where infection is likely to be polymicrobial (e.g., DFI or infection of the pelvis and perianal region), broadspectrum antibiotic coverage is warranted. Although beta-lactams have traditionally been the mainstay of broad-spectrum therapy, fluoroquinolones with enhanced Gram-positive 
activity are increasingly used as first-line agents in these cases [14].

Moxifloxacin (Avelox ${ }^{\circledR}$, Bayer Pharma AG, Leverkusen, Germany) is a broad-spectrum fluoroquinolone possessing greater in vitro activity against Gram-positive aerobic pathogens than earlier fluoroquinolones (e.g., ciprofloxacin) and it also has potent activity against Gram-negative bacteria [15]. Additional activity against anaerobes makes moxifloxacin particularly useful for infections of mixed aerobic and anaerobic etiology [14]. Moxifloxacin achieves good penetration into muscle, subcutaneous adipose tissue, and inflammatory blister fluid, suggesting that adequate tissue concentrations can be achieved in cSSSIs [15]. Evidence for its clinical efficacy in cSSSIs has been demonstrated in a series of randomized, Phase III controlled trials [16-18].

Here we report the results of the Avelox in Routine Treatment of cSSSIs (ARTOS) study, which aimed at obtaining data first, on the characteristics of patients treated with moxifloxacin in a large cohort of patients coming from various geographic regions and second, on the effectiveness, safety, and tolerability of moxifloxacin under daily life treatment conditions in patients with cSSSIs.

\section{METHODS}

\section{Study Design}

ARTOS was an international, prospective, noninterventional, non-controlled observational study carried out between 2005 and 2009 in hospitalized patients or in outpatients under real-life conditions requiring initial IV antibiotic therapy for cSSSIs. The study was conducted at more than 600 investigational sites across Europe, the Middle East, and Asia-Pacific region.
Study investigators could enroll any patient with a diagnosis of cSSSI, for whom the treating physician had decided to begin moxifloxacin therapy in accordance with its approved indications and according to local guidelines before inclusion into, and independent of, the study. Diagnosis of cSSSI was made at the discretion of the clinician, and it was assumed that most clinical conditions would include skin abscess, post-surgical, or post-traumatic wound infection, bite wound infection, erysipelas/cellulitis, or DFI. Lesion size and level of tissue involvement (epidermis, dermis, fascia, fat, muscle, and bone) were recorded, as well as co-morbidities, risk factors, and details on any surgical intervention.

The study was conducted in accordance with the guidelines of the European Medicines Agency [19] as well as applicable laws and regulations. Where required and before the start of the study, notification and/or approval of the protocol was also obtained from the relevant local competent authorities, ethics committees and/or institutional review boards in each country. Patients gave written informed consent if it was required by local law at the time of study start before documentation of effectiveness and safety findings.

\section{Treatment Schedule and Assessments}

The study protocol defined that moxifloxacin should be administered in accordance with the recommendations prevailing at the time of the study and specified in the summary of product characteristics for each country. In Europe, for example, the recommended dosage and treatment duration is a once-daily $400 \mathrm{mg}$ IV infusion of moxifloxacin with a switch to $400 \mathrm{mg}$ per os (PO) at approximately 6 days in a course lasting from 7 to 21 days [20]. 
For each patient, the treating physician used a standardized case report form (CRF) to record data with respect to demographics, pretreatment with another antibiotic drug, concomitant diseases, moxifloxacin treatment, and adverse events (AEs). Effectiveness and tolerability were recorded at an initial visit and one or two follow-up visits, with scheduling carried out at the discretion of the treating physician in line with daily routine practice. Effectiveness assessments included severity of infection, clinical signs and symptoms, duration until improvement, duration until recovery, duration until wound closure, and overall response to treatment. At the last clinic visit, physicians were asked to evaluate moxifloxacin treatment by cSSSI diagnosis, classifying effectiveness as 'very good', 'good', 'sufficient', or 'insufficient'. Treating physicians were also asked to record if they would consider using moxifloxacin again for another patient. Safety assessments included overall tolerability of moxifloxacin together with the frequency of AEs, their seriousness, and what action was taken in respect of AEs and their outcome.

\section{Data Analyses}

The ARTOS study enrolled a total 6,594 patients, of whom 5,444 had data available for safety and effectiveness analysis. Analyses, all of which were descriptive and not subject to formal statistical testing, were based on the analyzed population of 5,444 patients. This included all patients diagnosed with cSSSI and who had received at least one dose of moxifloxacin during the observational period. Of the 467 patients excluded from the analyzed population, the majority $(n=345)$ did not have an established diagnosis of cSSSI. Patients who received moxifloxacin exclusively orally $(n=683)$ were also excluded from the analysis as initial oral administration of moxifloxacin is not approved in the label for cSSSIs. Other reasons for exclusion included retrospective documentation, in which the initial visit or all visits had occurred more than 2 days before the actual start of study or after the official study end, lack of symptom documentation at the initial visit, no record of intake or assessment of response to moxifloxacin, and lost to follow-up.

\section{RESULTS}

\section{Patients}

Of the 5,444 patients for whom data were used in the effectiveness and safety analyses, 3,499 were treated in Europe with the majority $(2,019)$ treated in Germany. Of the remaining 1,480 patients, 1,017 were treated in the Middle East (Saudi Arabia, Yemen, and United Arab Emirates) and the rest in Pakistan (276), the Philippines (481), Indonesia (102), and Taiwan (69).

Patients' demographic parameters and their medical history are summarized in Table 1 . More male patients than females were enrolled; the mean age was $55.6 \pm 17.9$ years. Comorbidity was common amongst the study population, with 3,917 (72.0\%) patients having at least one concurrent disease or disorder. Cardiac and vascular diseases were the most common comorbidities, followed by endocrine and metabolic disorders (Table 1). Among risk factors known to predispose to cSSSI, diabetes mellitus was documented most frequently followed by peripheral vascular disease (Table 1). Consistent with the presence of any comorbidity $>75 \%$ of patients received concomitant therapies, most frequently for the gastrointestinal tract, metabolism, and cardiovascular system [e.g., insulin was prescribed for 1,037 (19.0\%) patients, acetylsalicylic acid for 677 patients 


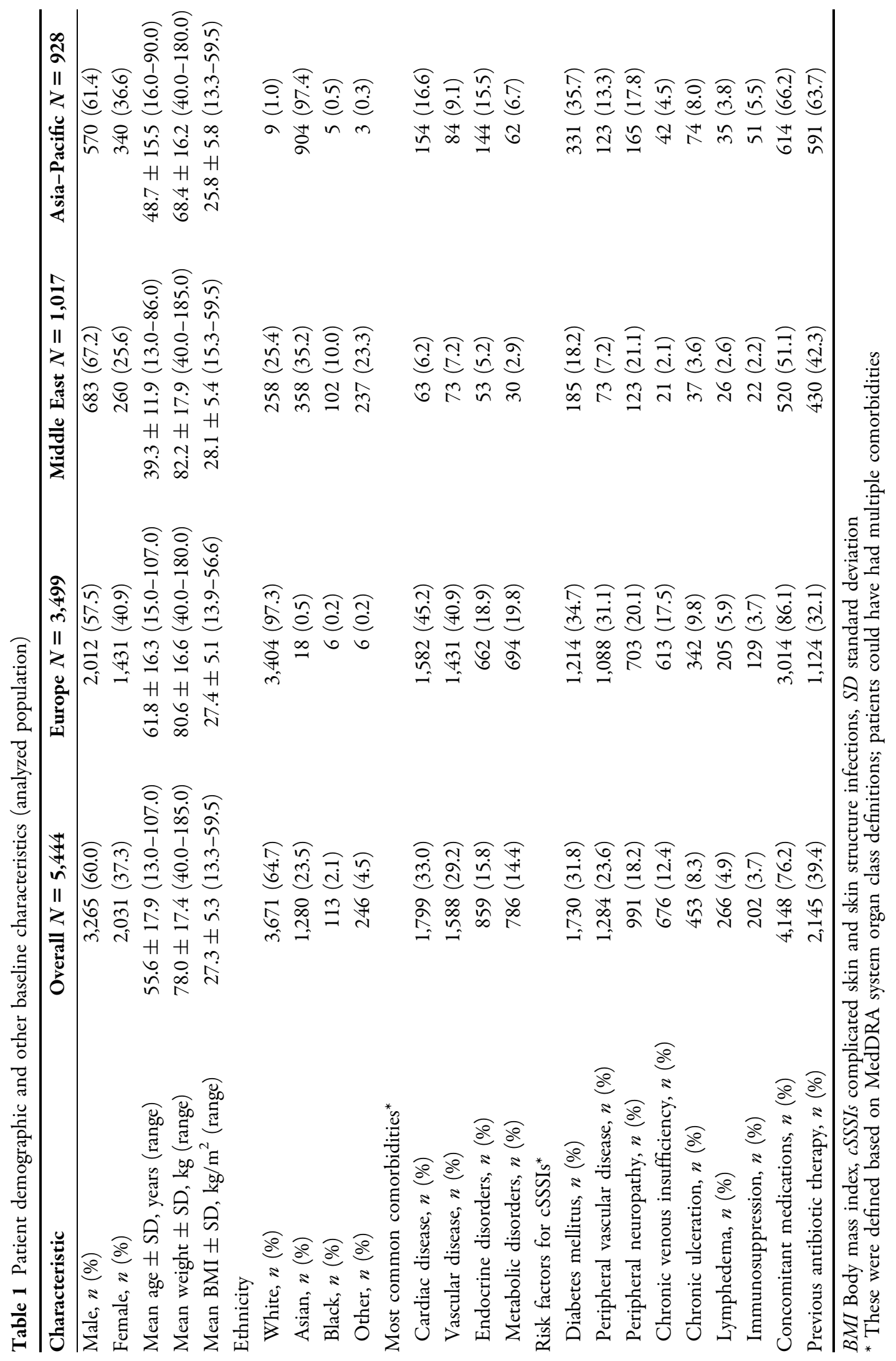


(12.4\%), and enoxaparin for 568 patients (10.4\%)]. More than a third of patients had received prior antibiotic therapy for the current cSSSI, with cephalosporins and penicillins administered to 929 (17.1\%) and 812 (14.9\%) patients, respectively. A higher proportion of patients in the Asia-Pacific region had received prior antibiotic therapy compared with those in the Middle East and Europe (Table 1). Pre-treated patients tended to have infections of greater severity in comparison with patients who had not received prior antibiotic therapy. Across the three regions, severe disease was reported more frequently in Europe (47.4\%) compared with $38.1 \%$ in the Middle East, and 37\% in AsiaPacific, respectively.

Patients presenting with post-surgical wound infections accounted for the most frequently recorded cSSSIs, closely followed by skin abscesses and DFI (Table 2). Among patients aged $<60$ years, skin abscesses $(28.0 \%)$ and postsurgical wound infections $(22.9 \%)$ were the most common cSSSIs. In patients aged $\geq 60$ years, DFI were the most common $(28.6 \%)$.

Of the 1,103 patients with DFI, $701(63.6 \%)$ suffered peripheral neuropathy and 614 (55.7\%) peripheral vascular disease. In the 791 (71.7\%) patients for whom hemoglobin A1c (HbA1c) levels were available, mean values were increased in both male and female patients $(8.4 \pm 2.1)$.

Most patients had lesions that were $<40 \mathrm{~cm}^{2}$ in size, although $22.4 \%$ had lesions of between 40.0 and $200 \mathrm{~cm}^{2}$. Lesions of $\geq 200 \mathrm{~cm}^{2}$ were reported in $7.6 \%$ of patients. In nearly $90 \%$ of patients, infection involved the dermis, the fat layer, or bone (Table 2). Signs and symptoms consistent with cSSSIs were present in most patients before the start of treatment with moxifloxacin (Table 3). Based on size of lesion, level of tissue involvement, and accompanying signs and symptoms, 4,830 (88.7\%) patients were assessed by the treating physician as having moderate or severe infections. DFI was the diagnosis most frequently classed as severe.

\section{Treatment}

Of the 5,444 patients, 4,692 (86.2\%) received sequential IV followed by PO moxifloxacin. This was administered for an average [mean \pm standard deviation (SD)] of $10.6 \pm 4.6$ days (median 10.0 days) (Table 4 ). The IV antibiotic therapy was switched to PO therapy after an average of $3.4 \pm 2.5$ days in these patients (median 3 days). Of the 752 (13.8\%) patients who received moxifloxacin exclusively via the IV route, treatment was maintained for an average of $7.5 \pm 4.2$ days (median 6.0 days). While patients with posttraumatic wounds, infected ulcers, and DFI required the longest period of treatment, those patients with skin abscesses and bite wounds had the shortest courses of treatment (Table 4). Independently of the route of administration, almost all patients received the recommended daily dose of $400 \mathrm{mg}$ moxifloxacin.

Comparisons across the three geographical regions showed that the mean duration of sequential IV/PO treatment was shorter in the Middle East (9.2 \pm 3.5 days) than in either Europe $(10.9 \pm 4.6$ days $)$ or the Asia-Pacific countries (11.6 \pm 5.0 days), with the switch to PO treatment occurring earlier there too. Patients treated in the Middle East were switched from IV to PO moxifloxacin after an average of only $1.9 \pm 1.7$ days' therapy versus $3.7 \pm 2.6$ days in Europe and $4.0 \pm 2.5$ days in the Asia-Pacific countries.

The majority of patients had surgery in addition to treatment with moxifloxacin, with debridement being the most frequent procedure [ $n=2044$ patients (37.5\%)]. A further 1,367 (25.1\%) patients had their lesions drained and 
Table 2 Complicated skin and skin structure infections diagnoses, lesion size, and degree of tissue involvement

\begin{tabular}{|c|c|c|c|c|}
\hline Characteristic & $\begin{array}{l}\text { Overall } \\
N=5,444\end{array}$ & $\begin{array}{l}\text { Europe } \\
N=3,499\end{array}$ & $\begin{array}{l}\text { Middle East } \\
N=\mathbf{1 , 0 1 7}\end{array}$ & $\begin{array}{l}\text { Asia-Pacific } \\
N=928\end{array}$ \\
\hline Post-surgical wound infection, $n(\%)$ & $1,356(24.9)$ & $987(28.2)$ & $149(14.7)$ & $220(23.7)$ \\
\hline Skin abscess, $n(\%)$ & $1,148(21.1)$ & $538(15.4)$ & $441(43.4)$ & $169(18.2)$ \\
\hline Diabetic foot infection, $n(\%)$ & $1,103(20.3)$ & $754(21.5)$ & $125(12.3)$ & $224(24.1)$ \\
\hline Erysipelas/cellulitis, $n$ (\%) & $820(15.1)$ & $550(15.7)$ & $133(13.1)$ & $137(14.8)$ \\
\hline Post-traumatic wound infection, $n(\%)$ & $581(10.7)$ & $987(28.2)$ & $77(7.6)$ & $114(12.3)$ \\
\hline Bite wound infections, $n(\%)$ & $154(2.8)$ & $117(3.3)$ & $13(1.3)$ & $24(2.6)$ \\
\hline Infected ulcer, $n(\%)$ & $81(1.5)$ & $71(2.0)$ & $4(0.4)$ & $6(0.6)$ \\
\hline Other infections, $n(\%)$ & $193(3.5)$ & $89(2.5)$ & $70(6.9)$ & $34(3.7)$ \\
\hline \multicolumn{5}{|l|}{ Lesion size } \\
\hline$<20.0 \mathrm{~cm}^{2}, n(\%)$ & $2,280(41.9)$ & $1,370(39.2)$ & $564(55.5)$ & $346(37.3)$ \\
\hline $20.0-40.0 \mathrm{~cm}^{2}, n(\%)$ & $966(17.7)$ & $589(16.8)$ & $167(16.4)$ & $210(22.6)$ \\
\hline $40.0-200.0 \mathrm{~cm}^{2}, n(\%)$ & $1,222(22.4)$ & $839(24.0)$ & $130(12.8)$ & $253(27.3)$ \\
\hline$\geq 200.0 \mathrm{~cm}^{2}, n(\%)$ & $415(7.6)$ & $318(9.1)$ & $17(1.7)$ & $80(8.6)$ \\
\hline \multicolumn{5}{|l|}{ Deepest tissue involvement } \\
\hline Dermis, $n(\%)$ & $1,681(30.9)$ & $1,111(31.8)$ & $280(27.5)$ & $290(31.3)$ \\
\hline Fat, $n(\%)$ & $1,254(23.0)$ & $804(23.0)$ & $291(28.6)$ & $159(17.1)$ \\
\hline Muscle, $n(\%)$ & $667(12.3)$ & $434(12.4)$ & $53(5.2)$ & $180(19.4)$ \\
\hline Bone, $n(\%)$ & $490(9.0)$ & $408(11.7)$ & $27(2.7)$ & $55(5.9)$ \\
\hline \multicolumn{5}{|l|}{ Surgical procedures } \\
\hline Debridement, $n(\%)$ & $2,044(37.5)$ & $1,409(40.3)$ & $204(20.1)$ & $268(28.9)$ \\
\hline Drainage, $n(\%)$ & $1,367(25.1)$ & $688(19.7)$ & $411(40.4)$ & $431(46.4)$ \\
\hline Other, $n(\%)$ & $813(14.9)$ & $649(18.5)$ & $92(9.0)$ & $72(7.8)$ \\
\hline
\end{tabular}

$813(14.9 \%)$ patients underwent unspecified surgical procedures. Overall rates of surgical intervention were similar in the three geographical regions.

\section{Effectiveness}

Treatment with IV/PO moxifloxacin was associated with high rates of improvement and recovery as assessed by treating physicians in all three geographic regions. Across the three regions, $93.2 \%$ of patients had experienced either complete resolution of symptoms or improvement at follow-up. The condition in $244(4.5 \%)$ patients remained unchanged at follow-up, while symptoms had worsened in 36 $(0.7 \%)$ patients. There were no marked regional differences in the percentage of patients 
experiencing improvement (Europe: 30.0\%, Asia-Pacific: 27.3\%, Middle East: $28.4 \%$ ) or recovery (Europe: 61.5\%, Asia-Pacific: 68.7\%, Middle East: $64.8 \%$ ) following treatment with moxifloxacin.

Table 3 Signs and symptoms of cSSSIs

\begin{tabular}{ll}
\hline Signs and symptoms & $\begin{array}{l}\text { Analyzed population } \\
\boldsymbol{N}=\mathbf{5 , 4 4 4}\end{array}$ \\
\hline Erythema, $n(\%)$ & $5,140(94.4)$ \\
Edema, $n(\%)$ & $4,786(87.9)$ \\
Local warmth, $n(\%)$ & $4,941(90.8)$ \\
Pressure pain, $n(\%)$ & $4,939(90.7)$ \\
Purulence, $n(\%)$ & $3,787(69.6)$ \\
Fever*, $n(\%)$ & $3,455(63.5)$ \\
WBC count $>9,000 / \mu \mathrm{L}$, & $3,431(63.0)$ \\
$n(\%)$ & \\
\hline
\end{tabular}

WBC white blood cell; cSSSIs complicated skin and skin structure infections

${ }^{*}$ Fever: body temperature $\geq 37.5^{\circ} \mathrm{C}$; mild: $37.5-38.0{ }^{\circ} \mathrm{C}$; moderate: $38.1-39.0^{\circ} \mathrm{C}$; severe: $\geq 39.1{ }^{\circ} \mathrm{C}$
Wound closure was assessed in 3,338 patients (61.3\%) during follow-up. Over a period of approximately 21 days, wound closure was documented in 1,575 (47.1\%) patients with a mean duration to closure of $11.2 \pm 7.3$ days (median 10.0 days). Patients with DFI underwent a longer recovery until wound closure, with a mean duration of $15.7 \pm 10.5$ days.

In general, treatment with moxifloxacin was associated with rapid symptom improvement. Over the course of treatment, erythema had resolved or improved in $91.9 \%(4,723 / 5,140)$ of patients, edema in $90.0 \%(4,306 / 4,786)$, local warmth in $93.0 \%(4,594 / 4,941)$, purulence in $94.2 \%(3,569 / 3,787)$, pressure pain in $90.8 \%$ $(4,483 / 4,939)$, and fever in $95.3 \%(3,292 / 3,455)$ of patients. Among the $63.0 \%$ of patients who had an elevated white blood cell count at study enrolment, $87.9 \%$ had experienced a decrease by end of therapy. Symptomatic improvement was observed within an average of $4.2 \pm 2.6$ days of the start of treatment (median 3.0 days) with patients having full recovery within an average of $8.6 \pm 4.4$ days (median 7.0 days). Patients with

Table 4 Duration of sequential IV/PO and exclusively IV moxifloxacin treatment in patients with cSSSIs

\begin{tabular}{|c|c|c|}
\hline \multirow[t]{2}{*}{ Diagnosis } & \multicolumn{2}{|c|}{ Mean treatment duration $\pm S D$, days (range) } \\
\hline & Sequential IV/PO $N=4,680^{*}$ & IV $N=751^{* *}$ \\
\hline All diagnoses & $10.6 \pm 4.6(2.0-58.0)$ & $7.5 \pm 4.2(1.0-42.0)$ \\
\hline Post-surgical wound infection & $10.2 \pm 3.9(3.0-42.0)$ & $7.0 \pm 3.9(1.0-42.0)$ \\
\hline Skin abscess & $9.2 \pm 3.4(2.0-35.0)$ & $6.0 \pm 3.4(1.0-25.0)$ \\
\hline Diabetic foot infection & $12.9 \pm 5.9(2.0-58.0)$ & $8.5 \pm 3.9(1.0-21.0)$ \\
\hline Erysipelas/cellulitis & $10.6 \pm 4.0(2.0-43.0)$ & $7.5 \pm 4.4(1.0-30.0)$ \\
\hline Post-traumatic wound infection & $10.6 \pm 4.1(3.0-40.0)$ & $9.2 \pm 5.2(1.0-30.0)$ \\
\hline Bite wound infections & $9.2 \pm 3.5(2.0-22.0)$ & $7.5 \pm 3.4(2.0-14.0)$ \\
\hline Infected ulcer & $11.1 \pm 4.7(5.0-31.0)$ & $9.4 \pm 5.3(1.0-18.0)$ \\
\hline Other infections & $10.5 \pm 5.6(3.0-40.0)$ & $6.6 \pm 4.1(1.0-20.0)$ \\
\hline
\end{tabular}

$I V$ Intravenous, $P O$ per os, cSSSIs complicated skin and skin structure infections

* Data missing for 12 patients

** Data missing for 1 patient 
Table 5 Physicians' overall assessment of the effectiveness of moxifloxacin in complicated skin and skin structure infections

\begin{tabular}{|c|c|c|c|c|}
\hline \multirow[t]{2}{*}{ Diagnosis } & \multicolumn{4}{|c|}{ Effectiveness rating (\%) } \\
\hline & $\begin{array}{l}\text { Very } \\
\text { good }\end{array}$ & Good & Sufficient & Insufficient \\
\hline All diagnoses & 64.1 & 26.8 & 5.5 & 3.3 \\
\hline $\begin{array}{l}\text { Post-surgical } \\
\text { wound } \\
\text { infection }\end{array}$ & 67.4 & 24.6 & 5.6 & 2.4 \\
\hline Skin abscess & 69.6 & 24.9 & 2.9 & 1.9 \\
\hline $\begin{array}{l}\text { Diabetic foot } \\
\text { infection }\end{array}$ & 50.9 & 31.7 & 9.9 & 7.1 \\
\hline $\begin{array}{c}\text { Erysipelas/ } \\
\text { cellulitis }\end{array}$ & 67.8 & 25.9 & 3.3 & 2.9 \\
\hline $\begin{array}{l}\text { Post-traumatic } \\
\text { wound } \\
\text { infection }\end{array}$ & 67.3 & 26.7 & 4.5 & 1.4 \\
\hline $\begin{array}{l}\text { Bite wound } \\
\text { infections }\end{array}$ & 67.5 & 28.6 & 3.2 & 0.6 \\
\hline Infected ulcer & 50.6 & 35.8 & 9.9 & 2.5 \\
\hline $\begin{array}{l}\text { Other } \\
\text { infections }\end{array}$ & 60.1 & 24.9 & 7.8 & 6.7 \\
\hline
\end{tabular}

DFI took longer than all other patients to recover (mean 10.6 \pm 5.8 days), while disease severity, older age, and depth of tissue involvement also delayed time to recovery. Analysis by region showed that recovery occurred most rapidly in patients in the Middle East (mean $7.3 \pm 3.8$ days) followed by those in Europe (mean $8.7 \pm 4.3$ days) and Asia-Pacific (mean 9.5 \pm 5.1 days).

A responder versus non-responder retrospective analysis has shown that concomitant diseases were more frequent in patients who did not respond to therapy $(n=179)$. Thus, the frequency in this group of patients was higher for peripheral neuropathy (17.6 vs $35.2 \%)$, peripheral vascular disease ( 22.5 vs $54.2 \%$ ), presence of chronic ulceration ( 7.8 vs
Table 6 Incidence of treatment-emergent AEs among patients with cSSSIs treated with moxifloxacin

\begin{tabular}{lc}
\hline Adverse events (AE) & $\begin{array}{l}\text { Patients, } \\
n(\%)\end{array}$ \\
\hline All AEs & $144(2.6)$ \\
ADRs & $110(2.0)$ \\
Serious AEs & $27(0.5)$ \\
Serious ADRs* & $8(<0.2)$ \\
Permanent discontinuation of therapy & $55(1.0)$ \\
due to AE & $13(0.2)$ \\
AEs with fatal outcome & $2(<0.1)$ \\
ADRs with fatal outcome
\end{tabular}

Total number of patients included was 5,444

ADRs Adverse drug reactions, cSSSIs complicated skin and skin structure infections

* Infection-related events occurred in three patients, gastrointestinal disorders in two patients, and administration site conditions in two patients. Other serious ADRs included hypersensitivity reactions, dehydration, headache, acute renal failure, pruritis, and rash

$22.9 \%$ ), and diabetes mellitus (31.0 vs $55.9 \%$ ) respectively.

Overall, treating physicians rated moxifloxacin as 'very good' or 'good' in 4,950 $(90.9 \%)$ of the 5444 patients with effectiveness ratings ranging from $82.6 \%$ for DFI to $96.1 \%$ for bite wound infections (Table 5). In general, effectiveness ratings were higher for younger patients than for older ones and for those with mild and moderate infections in comparison with those with severe infections.

\section{Safety and Tolerability}

AEs were documented in 144 patients (2.6\%), with $110(2.0 \%)$ of these identified as adverse drug reactions (ADRs). Serious AEs were documented in $0.5 \%$ and serious ADRs in $<0.2 \%$ of patients (Table 6). AEs led to permanent discontinuation of treatment in 55 patients, which was attributed to an ADR in 46 
patients. A total of 13 deaths occurred during the observation period, two of which were drugrelated; both of these deaths occurred in elderly patients with DFI and significant comorbidity. One patient died from sepsis due to infection with methicillin-resistant $S$. aureus (MRSA) and the second from complications arising from toxic megacolon.

Gastrointestinal events were the most frequent ADRs occurring during treatment with moxifloxacin, with diarrhea and nausea affecting $27(0.5 \%)$ and $21(0.39 \%)$ patients, respectively. Adverse central nervous system events such as headache and dizziness were the next most frequent, affecting $10(0.18 \%)$ and $8(0.15 \%)$ patients, respectively. In the majority of patients these ADRs had either resolved or improved by the end of the observation period.

\section{DISCUSSION}

ARTOS was an international, prospective, noninterventional, non-controlled observational cohort study in patients with cSSSIs. Observational studies differ from randomized controlled trials (RCTs) in that a RCT can study the effect of a new intervention on pre-defined parameters in a random sample of well-selected study subjects, whereas observational studies simply observe the effect of the treatment on a broader population [21]. Consequently, RCTs are considered the gold standard for determining causality between the intervention and clinical efficacy. Observational studies can still provide valuable information relevant to real-world settings about the use of a medication in routine clinical practice (e.g., characteristics of patients who receive this medication) and also in countries which in general are not involved in clinical development programs (e.g., the Middle East). In addition, these Phase IV studies are requested by regulatory authorities [22]. In the ARTOS study, for example, patients had participated who would not ordinarily have been enrolled in a randomized controlled trial because of significant comorbidity, and the extent and nature of their cSSSIs (e.g., patients with necrotizing fasciitis).

In this study, the most frequently diagnosed cSSSIs were post-surgical wound infections, skin abscesses, and DFI. When considering the new Food and Drug Administration diagnostic criteria applied for enrollment into acute bacterial skin and skin structure infection clinical studies [23], many of the patients enrolled into the ARTOS study had signs and symptoms of a severe infection. Thus, almost half of the erysipelas patients had erythema, edema, and induration of $\geq 75 \mathrm{~cm}^{2}$ (and a systemic sign such as fever $\geq 38^{\circ} \mathrm{C}$ ). Furthermore, approximately $70 \%$ of patients with a wound infection had purulent discharge, erythema, edema, and an induration of $\geq 75 \mathrm{~cm}^{2}$ with systemic sign, such as fever $\geq 38^{\circ} \mathrm{C}$. Frequencies varied between regions, with skin abscesses notably prevalent among patients in the Middle East. Peripheral neuropathy $(\sim 65 \%)$ and peripheral vascular disease $(\sim 55 \%)$ affected almost two-thirds and more than a half of all patients with DFI, and osteomyelitis was present in nearly $30 \%$ of these patients. The ARTOS study also revealed that diabetes was often poorly controlled or managed as both HbA1c values and fasting blood glucose levels were higher than the respective target values (e.g., $6.5 \%$ and $7 \mathrm{mM}$, respectively) in $>60 \%$ of these patients.

The increased susceptibility to more severe infections among patients with significant comorbidities (e.g., diabetes) or elderly patients is reflected in this study population, who were also likely to receive a prior course of antibiotic (approximately 40\% of patients) for 
their current cSSSI before moxifloxacin treatment. This suggests that many patients seen in routine clinical practice have difficultto-treat cSSSIs. A higher proportion of elderly patients enrolled in Europe had severe cSSSIs than of those in the Middle East and AsiaPacific region.

When comorbidities were taken into account regarding DFI patients, which may influence the length of therapy and clinical outcome, we have observed a similar result to that for the DFI patients enrolled in the RELIEF trial which was a randomized, double-blind study $[18,24]$. Thus, comparing patients enrolled in the RELIEF and ARTOS studies regarding specific comorbidities of DFI patients, the proportion of patients with peripheral vascular disease (>65.5 vs $55.7 \%$, respectively), peripheral neuropathy (49.5 vs $63.5 \%$, respectively), or osteomyelitis (20 vs $28.8 \%$, respectively) were rather similar.

Results from the ARTOS study have shown that moxifloxacin was an effective treatment for patients, including those with DFI which is one of the most refractory infections to antibiotic therapy. A total of $93 \%$ of patients experienced either a complete resolution or an improvement in their symptoms, with symptomatic improvement seen rapidly in a matter of a few days. Patients treated in the Middle East experienced the shortest time to recovery, which may be due to the higher frequency of more easily treatable cSSSIs (e.g., skin abscesses). DFI was the most frequent diagnosis in the Asia-Pacific region and patients there had longer response times in comparison with the other regions. Data from randomized clinical trials have shown that moxifloxacin achieves clinical cure in $79-82 \%$ of patients with cSSSIs $[16-18,24]$, rates that are comparable with the results obtained in the ARTOS study. As mentioned above, the majority of investigators in the ARTOS study have rated the overall effectiveness of moxifloxacin as 'very good' or 'good.' Based on the type of diagnosis it was found 'very good' or 'good' in $82.6 \%$ of DFI and $86.4 \%$ of infected ulcer patients, while the effectiveness was rated similarly for a higher proportion of patients with abscesses $(94.5 \%)$ or wound infections (92-96.1\%).

Across the three geographical regions, the majority of the patients were treated with sequential IV/PO moxifloxacin $400 \mathrm{mg}$, switching them from IV to PO therapy after an average of 3-4 days. On average, sequential therapy was administered for about 10 days. However, treatment durations of 14 days is required commonly [24, 25].

Consistent with the results from the earlier trials, moxifloxacin was generally well tolerated by patients in this study. In fact, the frequency of AEs, ADRs, and deaths was lower in the ARTOS study than those reported in the RCTs, as were rates of permanent discontinuation of therapy. A unique feature of large, noninterventional studies is that they allow for the identification of rare safety events that would not be seen in smaller patient populations in RCTs. In this respect, no unexpected safety events were seen in the ARTOS study. The nature of AEs, including serious AEs, was consistent with the established safety profile of moxifloxacin as described recently [26].

Observational studies, in addition to the strengths as described earlier, also have a number of limitations. For example, in the ARTOS study the lack of centralized diagnostic criteria or stratification by disease severity was one of the limitations. Interpretation and analysis of observational studies is somewhat difficult due to the heterogeneity of patients in real-life settings. Other limitations were the lack of active comparator and microbiological data; thus, effectiveness in relation to microbiological 
eradication was impossible to ascertain. Indeed, undertaking microbiological analysis is not feasible in observational studies involving several thousand patients. Reliable data collection on microbiological patterns would have required the use of specific sampling methods excluding swabbing, which cannot be requested in non-interventional studies. Furthermore, even if information on species is available, susceptibility varies between regions and methodological differences could complicate the analysis. The bacterial etiology of cSSSIs is well known [1, 4, 15]. Moxifloxacin, a broad-spectrum antibiotic, has activity against the most prevalent pathogens such as methicillin-susceptible $S$. aureus, E. coli, Bacteroides spp. It has limited activity against MRSA and, therefore, moxifloxacin is not the appropriate option for the treatment of cSSSI caused by this pathogen. The conclusions of this study do not probably apply to regions where MRSA-caused infections are predominant [27]. In the absence of bacteriological results, diagnosis of cSSSI and choice of therapy in the current study were based on the clinician's routine practice reflecting available local cSSSI guidelines $[10,13,28]$. Hence, empirical antibiotic therapy must be supported by accurate knowledge of the epidemiology and resistance patterns when treating infections that may be caused by multiple pathogens including resistant microorganisms. Information on the origin of the infection (i.e., community- vs hospital-acquired) was not documented in the present study; however, it is expected that, like in the previous cSSSI clinical trials conducted with moxifloxacin, the vast majority of patients had their wound infection acquired in the community and they were hospitalized at the study start to receive initial IV therapy. To mimic clinical practice, no strict rules were applied for $\mathrm{AE}$ reporting in the investigational sites-except for serious AEs, which legally had to be systematically notified by the investigators-and actual reporting was based on the investigators medical judgment. This could have created differences between physicians.

\section{CONCLUSION}

In conclusion, the ARTOS study has highlighted the characteristics of cSSSIs associated with the use of moxifloxacin in routine clinical practice, globally and in different regions of the world. In general, moxifloxacin was used according to clinical practice guidelines even in the absence of exact microbiological data. The study also confirms the effectiveness and tolerability of this antibiotic for patients with a range of cSSSIs when used in accordance with the approved summary of product characteristics [20] and appropriate local guidelines.

\section{ACKNOWLEDGMENTS}

This study was conducted with support of a research grant from Bayer Healthcare. Project Management including the set-up and conduct of the study was supervised by Kathrin Stauch and Stephanie Heldner from Global NonInterventional Studies at Bayer; data management activities were overseen by Susanne Kovacic. Dr. Schauerte Studien und Marketing in der Medizin, Germany, a contract research organization, was responsible for data capture and data management, statistical analysis, and reporting of study results. Highfield Communication, Oxford, UK (funded by Bayer Healthcare), provided editorial assistance in the preparation of this manuscript. Dr J. Bogner is the guarantor for this article and accepts responsibility for the integrity of the work as a whole. 
Conflict of interest. Dr J. Bogner received lecture honoraria from Abbott, Astellas, Bayer HealthCare, Boehringer Ingelheim, Bund Dt. Internisten, Bristol Myers Squibb, Gilead, Janssen, MAÄF, Novartis, MSD, Pfizer, Roche, and ViiV Healthcare. Drs A. Kutaiman and M. Esguerra-Alcalen have no conflict of interest. Pierre Arvis is employee of Bayer Santé, France. Dr S. Heldner is a global project manager for noninterventional studies at Bayer Pharma, Germany. Dr P. Arvis is a medical expert at Bayer Pharma.

Compliance with ethics guidelines. The study was conducted in accordance with the guidelines from the European Medicines Agency as well as applicable laws and regulations. Where required and before the start of the study, notification and/or approval of the protocol was also obtained from the relevant local competent authorities, ethics committees and/or institutional review boards in each country. Patients gave written informed consent if it was required by local law at the time of study start before documentation of effectiveness and safety findings.

Open Access. This article is distributed under the terms of the Creative Commons Attribution Noncommercial License which permits any noncommercial use, distribution, and reproduction in any medium, provided the original author(s) and the source are credited.

\section{REFERENCES}

1. Dryden MS. Complicated skin and soft tissue infection. J Antimicrob Chemother. 2010;65: iii35-44.

2. Engemann JJ, Carmeli Y, Cosgrove SE, et al. Adverse clinical and economic outcomes attributable to methicillin resistance among patients with
Staphylococcus aureus surgical site infection. Clin Infect Dis. 2003;36:592-8.

3. Leaper DJ, van Goor H, Reilly J, et al. Surgical site infection-a European perspective of incidence and economic burden. Int Wound J. 2004;1:247-73.

4. Lipsky BA, Weigelt JA, Gupta V, Killian A, Peng MM. Skin and soft tissue, bone, and joint infections in hospitalized patients: epidemiology and microbiological, clinical and economic outcomes. Infect Con Hosp Epidemiol. 2007;28:1290-8.

5. Cainzos M. Review of the guidelines for complicated skin and soft tissue infections and intra-abdominal infections-are they applicable today? Clin Microbiol Infect. 2008;14:9-18.

6. Napolitano LM. Severe soft tissue infections. Infect Dis Clin N Am. 2009;23:571-91.

7. Moet GJ, Jones RN, Biedenbacj DJ, Stilwell MG, Fritsche TR. Contemporary causes of skin and soft tissue infections in North America, Latin America, and Europe: Report from the SENTRY Antimicrobial Surveillance Program (1998-2004). Diag Microbiol Infect Dis. 2007;57:7-13.

8. Brook I. Microbiology of polymicrobial abscesses and implications for therapy. J Antimicrob Chemother. 2002;50:805-10.

9. Eron LJ, Lipsky BA, Low DE, Nathwani D, Tice AD, Volturo GA. Managing skin and soft tissue infections: expert panel recommendations on key decision points. J Antimicrob Chemother. 2003;52:i3-17.

10. Stevens DL, Bisno AL, Chambers HF, et al. Practice guidelines for the diagnosis and management of skin and soft-tissue infections. Clin Infect Dis. 2005;41:1373-406.

11. May AK, Stafford RE, Bulger EM, et al. Surgical Infection Society Guidelines. Treatment of complicated skin and soft tissue infections. Surg Infect. 2009;10:467-99.

12. Liu C, Bayer A, Cosgrove SE, et al. Clinical practice guidelines by the Infectious Diseases Society of America for the treatment of methicillin-resistant Staphylococcus aureus infections in adults and children. Clin Infect Dis. 2011;52:e18-55.

13. Lipsky BA, Peters EJ, Berendt AR, et al. Specific guidelines for the treatment of diabetic foot infections 2011. Diabetes Metab Res Rev. 2012;28:234-5.

14. Giordano P, Weber K, Gesin G, Kubert J. Skin and skin structure infections: treatment with newer 
generation fluoroquinolones. Ther Clin Risk Manag. 2007;3:309-17.

15. Guay D. Moxifloxacin in the treatment of skin and skin structure infections. Ther Clin Risk Manag. 2006;2:4117-34.

16. Vick-Fragoso R, Hernández-Oliva G, Cruz-Alcázar J, STIC Study Group, et al. Efficacy and safety of sequential intravenous/oral moxifloxacin vs intravenous/oral amoxicillin/clavulanate for complicated skin and skin structure infections. Infection. 2009;37:407-17.

17. Giordano P, Song J, Pertel P, Herrington J, Kowalsky $\mathrm{S}$. Sequential intravenous/oral moxifloxacin versus intravenous piperacillin-tazobactam followed by oral amoxicillin-clavulanate for the treatment of complicated skin and skin structure infections. Int J Antimicrob Agents. 2005;26:357-65.

18. Gyssens IC, Dryden $M$, Kujath $P$, et al. A randomised trial of the efficacy and safety of sequential IV/oral moxifloxacin monotherapy versus IV piperacillin/tazobactam followed by oral amoxicillin/clavulanate for complicated skin and skin structure infections. J Antimicrob Chemother. 2011;66:2632-42.

19. European Medicines Agency. Guideline on the evaluation of medicinal products indicated for treatment of bacterial infections. Available at: www.ema.europa.eu/docs/en_GB/document_library/ Scientific_guideline/2009/09/WC500003417.pdf. Last accessed 30 May 2013.

20. Avelox (moxifloxacin $400 \mathrm{mg} / 250 \mathrm{ml}$ solution for infusion) (product information). Leverkusen, Germany: Bayer Pharma AG; 2011.

21. Jepsen P, Johnsen SP, Gillman MW, Sørensen HT. Interpretation of observational studies. Heart. 2004;90:956-60.
22. Suvarna V. Phase IV of drug development. Perspect Clin Res. 2010;1:57-60.

23. US Department of Health and Human Services, Food and Drug Administration. Guidance for industry. Acute bacterial skin and skin structure infections: developing drugs for treatment. Available at: www.fda.gov/downloads/Drugs/ GuidanceComplianceRegulatoryInformation/ Guidances/UCM071185.pdf. Last accessed 30 May 2013.

24. Schaper NC, Dryden M, Kujath P, et al. Efficacy and safety of IV/PO moxifloxacin and IV piperacillin/ tazobactam followed by PO amoxicillin/clavulanic acid in the treatment of diabetic foot infections: results of the RELIEF study. Infection. 2013; 41:175-86.

25. Jenkins TC, Sabel AL, Sarcone EE, Price CS, Mehler PS, Burman WJ. Skin and soft-tissue infections requiring hospitalization at an academic medical center: opportunities for antimicrobial stewardship. Clin Infect Dis. 2010;51:895-903.

26. Tulkens PM, Arvis P, Kruesmann F. Moxifloxacin safety: an analysis of 14 years of clinical data. Drugs R D. 2012;12:71-100.

27. Moran GJ, Abrahamian FM, Lovecchio F, Talan DA. Acute bacterial skin infections: developments since the 2005 Infectious Diseases Society of America (IDSA) guidelines. J Emerg Med. 2013;44:e397-412.

28. Concia E. Therapy of SSTI and role of tigecycline. Infez Med. 2009;17:64-76. 